\title{
Patients' Attitudes on Medication Use: A survey from a Primary Healthcare Centre in Alexandria, Egypt Rehab A. Rayan
}

\section{Alexandria University, High Institute of Public Health, Dept. of Epidemiology}

\section{Introduction}

The World Health Organization (WHO) defines rational use of medicines (RUM) as patients administer proper therapies to their medical conditions, in doses, which fulfil their own needs, for a sufficient duration, and at the minimum expenses to the society. The WHO and other healthcare institutions have advocated RUM and have deployed several initiatives in this regard. Nevertheless, irrational prescription, distribution, and selling of medications, as well as inappropriate use by patients, have been identified globally. Unfortunately, the WHO has reported that few countries have adopted fundamental strategies for RUM such as routine surveillance of use. In Egypt, irrational medication use is a community concern. This study examines patients' attitudes regarding medication use to promote rational medication use.

\section{Methods}

In April 2019, a descriptive cross-sectional study involved 72 patients attending a primary health care centre in Alexandria who responded to a face-to-face questionnaire with the help of the study researcher. Patients were randomly selected and agreed to participate in the study. Demographic features (age and gender) and attitudes towards medication use were collected. The data were analysed using SPSS v.25. Frequency tables were used to display qualitative data. A chi-square test was used for comparisons and $\mathrm{P}<0.05$ was considered significant.

\section{Results}

The respondents' mean age was 44.94 years and $56.94 \%$ of them were females. $77.78 \%$ of the respondents stated that when they get sick, they seek medications from the pharmacy without consulting a physician. Moreover, $52.78 \%$ of the respondents reported that their relatives recommend medications for them while $48.61 \%$ of them recommended medications themselves for their sick relatives. Additionally, $66.67 \%$ of the respondents stated that they stopped their medications prior to their physicians' recommended time and $61.11 \%$ of them admitted keeping unused medications at home. $73.61 \%$ of the respondents reported reading medication's prospectus and $75 \%$ of them checked the medications' expiry date before using them. The attitudes of patients' regarding medication use demonstrated non-significant differences with respect to gender.

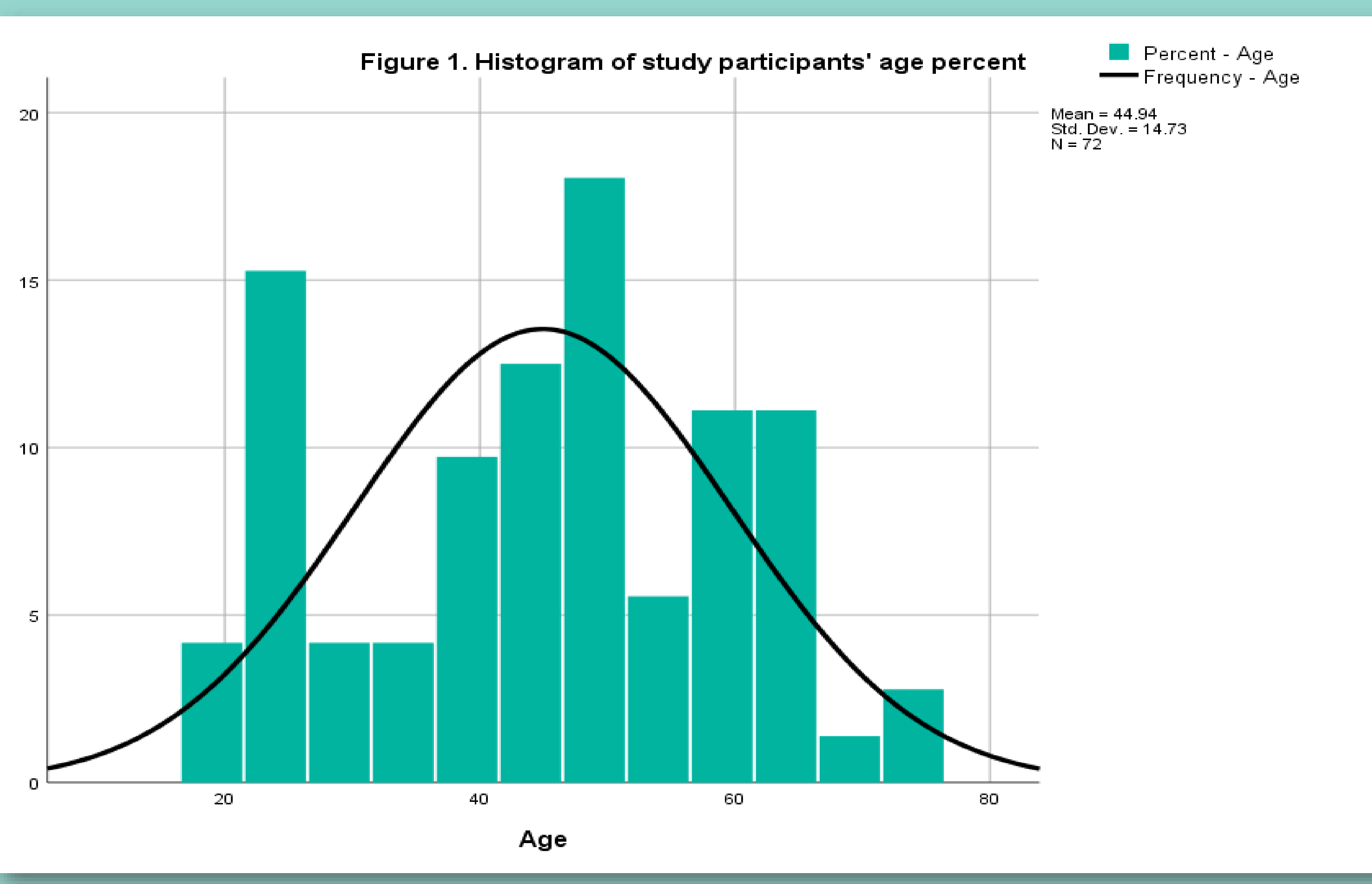

Figure 2. Boxplot of study participants' age per gender

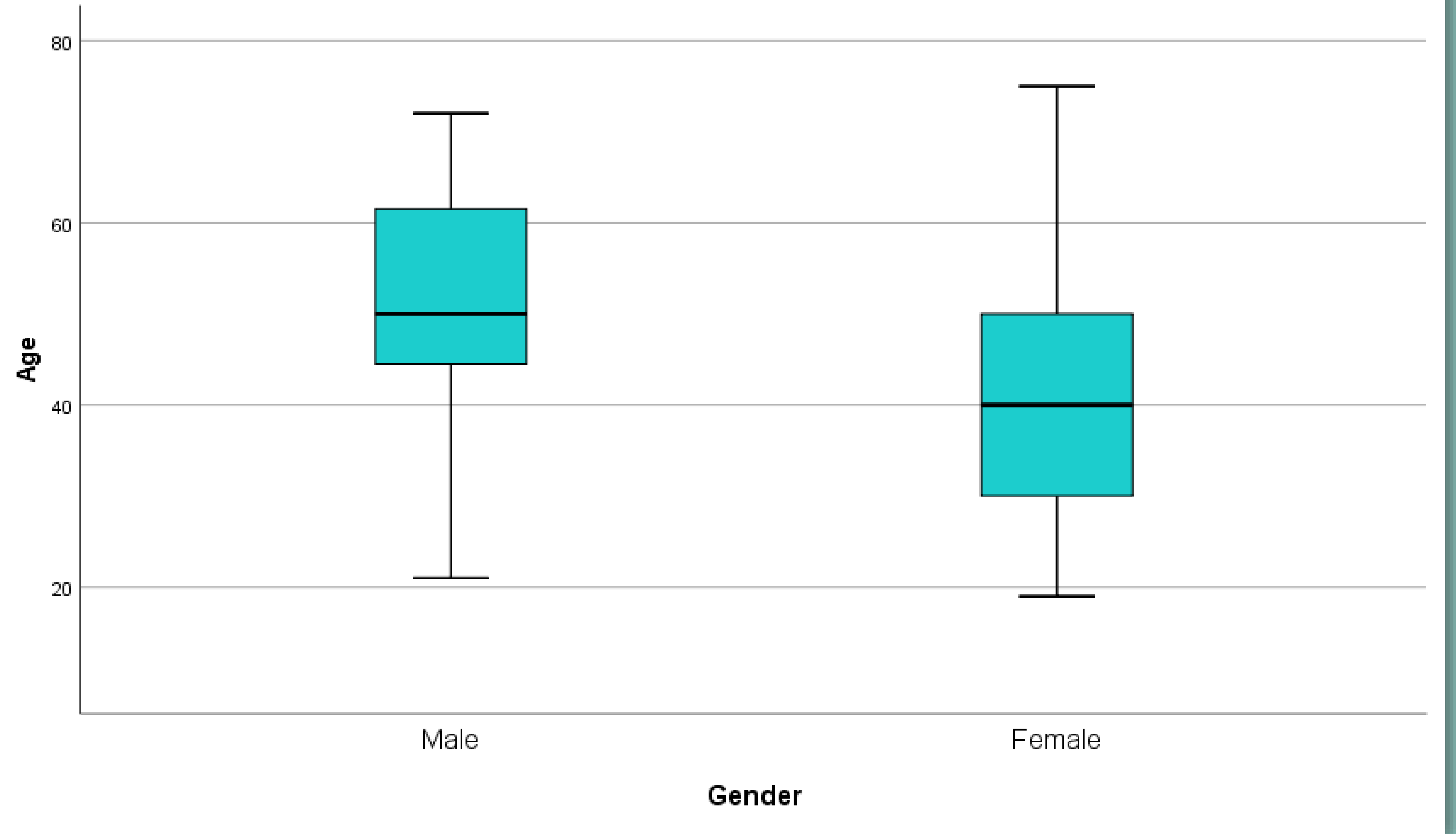

\section{Results (Continued)}

Table 1. Distribution of patients' attitudes towards medication use by gender.

Item

Buying medications from a pharmacy without consulting a physician when getting sick

Response Male n Female n Total

Yes

$11(35.5) \quad 11(26.8) \quad 22$

Sometimes $12(38.7) \quad 22(53.7) \quad \begin{array}{cc}34 \\ (47.2)\end{array}$

No $\quad 8(25.8) \quad 8(19.5) \quad \begin{gathered}16 \\ (22.2)\end{gathered}$

Yes $\quad 2(6.5) \quad 5(12.2) \quad \begin{gathered}7 \\ (9.7)\end{gathered}$

Relatives recommend medications Sometimes $12(38.7) \quad 19(46.3) \quad \begin{array}{cc}31 \\ (43.1)\end{array}$ No $\quad 17(54.8) \quad 17(41.5) \quad 34$ Yes $-8(25.8)-3(7.3)-\frac{11}{(15.3)}$

Recommending medications for relatives

\begin{tabular}{|c|c|c|c|}
\hline & & & \\
\hline Sometimes & $10(32.3)$ & $14(34.1)$ & $\begin{array}{c}24 \\
(33.3)\end{array}$ \\
\hline No & $13(41.9)$ & $24(58.5)$ & $\begin{array}{c}37 \\
(51.4)\end{array}$ \\
\hline Yes & $10(32.3)$ & $21(51.2)$ & $\begin{array}{c}31 \\
(43.1)\end{array}$ \\
\hline Sometimes & $8(25.8)$ & $9(22)$ & $\begin{array}{c}17 \\
(23.6)\end{array}$ \\
\hline No & $13(41.9)$ & $11(26.8)$ & $\begin{array}{c}24 \\
(33.3)\end{array}$ \\
\hline Yes & $23(74.2)$ & $30(73.2)$ & $\begin{array}{c}53 \\
(73.6)\end{array}$ \\
\hline Sometimes & $5(16.1)$ & $6(14.6)$ & $\begin{array}{c}11 \\
(15.3)\end{array}$ \\
\hline No & $3(9.7)$ & 5 (12.2) & $\begin{array}{c}8 \\
(11.1)\end{array}$ \\
\hline Yes & $10(32.3)$ & $18(43.9)$ & $\begin{array}{c}28 \\
(38.9)\end{array}$ \\
\hline Sometimes & 7 (22.6) & $9(22)$ & $\begin{array}{c}16 \\
(22.2)\end{array}$ \\
\hline No & $14(45.2)$ & $14(43.9)$ & $\begin{array}{c}28 \\
(38.9)\end{array}$ \\
\hline Yes & $25(80.6)$ & $29(70.7)$ & $\begin{array}{c}54 \\
(75)\end{array}$ \\
\hline Sometimes & $2(6.5)$ & 8 (19.5) & $\begin{array}{c}10 \\
(13.9)\end{array}$ \\
\hline No & $4(12.9)$ & $4(9.8)$ & $\begin{array}{c}8 \\
(11.1)\end{array}$ \\
\hline
\end{tabular}

Checking medications' expiry dates prior using them

Stopping medications use prior to the recommended time

Keeping unused drugs at home

Reading medication's prospectus

(11.1)

\section{Conclusions and Discussion}

According to this study, patients' attitudes concerning medication use were found far from rational. Most study respondents' practised self-prescription where they acquired medicines based on previous experience, recommending them to others or getting advice from non-professionals. Furthermore, most of the participants stopped taking their medicines when they felt better while keeping them for future use. Eventually, convinced attitudes can add to health hazards, needless consumption or spending. Therefore, Community awareness of rational medication use can minimize the found irrational use.

This study is mainly descriptive with only 72 participants, which might restrict generalizing study results'. Additionally, there was no framework to evaluate objectively the integrity of the participants' responses or to observe their habits while using medications. Consequently, further studies with larger samples should be applied to evaluate medication use behaviours, the underlying factors behind these behaviours, and their impact in the real world.

\section{References}

World Health Organization (WHO). Promoting rational use of medicines: core components. Geneva: World Health Organization (WHO). (2002).

WHO. Using indicators to measure country pharmaceutical situations: fact book on WHO Level I and Level II monitoring indicators. Geneva: WHO. (2006).

WHO. The role of education in the Rational Use of Medicines. WHO Regional Office for South-East Asia. (2006). 